\title{
Assessment of Immune Response and Efficacy of Essential Oils Application on Controlling Necrotic Enteritis Induced by Clostridium perfringens in Broiler Chickens
}

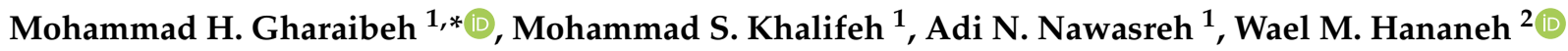 \\ and Mofleh S. Awawdeh ${ }^{2}$ \\ 1 Department of Basic Veterinary Medical Science, Faculty of Veterinary Medicine, Jordan University of Science \\ and Technology, P.O. Box 3030, Irbid 22110, Jordan; mskn@just.edu.jo (M.S.K.); \\ adi.nawasreh@yahoo.com (A.N.N.) \\ 2 Department of Pathology and Public Health, Faculty of Veterinary Medicine, Jordan University of Science \\ and Technology, P.O. Box 3030, Irbid 22110, Jordan; whananeh@just.edu.jo (W.M.H.); \\ mawawdeh@just.edu.jo (M.S.A.) \\ * Correspondence: mhgharaibeh@just.edu.jo; Tel.: +96-22-72-01000 (ext. 26768)
}

Citation: Gharaibeh, M.H.; Khalifeh, M.S.; Nawasreh, A.N.; Hananeh, W.M.; Awawdeh, M.S. Assessment of Immune Response and Efficacy of Essential Oils Application on Controlling Necrotic Enteritis Induced by Clostridium perfringens in Broiler Chickens. Molecules 2021, 26, 4527. https://doi.org/10.3390/ molecules26154527

Academic Editor:

Francesca Mancianti

Received: 31 May 2021

Accepted: 15 July 2021

Published: 27 July 2021

Publisher's Note: MDPI stays neutral with regard to jurisdictional claims in published maps and institutional affiliations.

Copyright: (c) 2021 by the authors. Licensee MDPI, Basel, Switzerland. This article is an open access article distributed under the terms and conditions of the Creative Commons Attribution (CC BY) license (https:/ / creativecommons.org/licenses/by/ $4.0 /)$.

Abstract: Necrotic enteritis (NE) caused by Clostridium perfringens is one of the most important enteric diseases in poultry. The antibacterial activity of two different essential oil (EO) blends against C. perfringens was investigated both in vitro and in vivo. Additionally, the immunological response to EO treatment was assessed. In the in vitro study, the antibacterial activity of EO formulas and commonly used antibiotics was evaluated against $C$. perfringens using disk diffusion assay, minimum inhibitory concentration (MIC) assay, and minimum bactericidal concentration (MBC) assay. In the in vivo study, NE experimental infection was performed on 440 Ross broiler chicks at 19 days of age for 4 continuous days. The chicks were treated with either EOs or amoxicillin at 22 days of age for 5 continuous days. One day after the end of treatment, the birds' performance was evaluated by calculating the feed conversion ratio. Serum samples from 120 birds were collected to measure the levels of IL-1 $\beta$, IFN- $\gamma$, IL-8, IL-10, and IL-17. After that, all birds were slaughtered, and their small intestines were subjected to gross and histopathological evaluation. In addition, bacterial counts in the small intestines were evaluated. In the in vitro study, EOs showed higher antimicrobial activities in comparison with antibiotics against $C$. perfringens. In the in vivo study, birds treated with EOs showed a significant decrease in bacterial counts, a significant decrease in intestinal lesions, and a significant improvement in performance compared with untreated birds $(p<0.05)$. Moreover, treating birds with EOs directed the immune system toward an anti-inflammatory pathway. None of the treated birds died due to NE compared with the $10 \%$ mortality rate in untreated birds. In conclusion, EOs might be an effective and safe alternative to antibiotics in the treatment of chicken NE.

Keywords: necrotic enteritis; Clostridium perfringens; essential oils; cytokines; anti-inflammatory pathway; broiler chickens

\section{Introduction}

Necrotic enteritis (NE) is one of the most important enteric diseases in poultry as it causes huge economic losses in the poultry industry, which could come close to USD 6 billion per year worldwide for medical treatments and impaired chicken performance [1] The main causative agent of NE disease is $C$. perfringens, which produces a novel toxin (NetB), which is a key virulence factor for experimental NE disease development [2]. C. perfringens is an opportunistic Gram-positive anaerobic bacterium that is normally present in the intestines of healthy humans and animals [3], but under certain abnormal conditions, C. perfringens may overgrow and multiply, which leads to NE development [4]. C. perfringens carries public threats to human health due to possible contamination of 
chicken products prepared for human consumption. C. perfringens is the second most common cause of foodborne disease in the US by causing about 1 million illnesses annually [5].

Traditionally, NE has been controlled by antimicrobial growth promoters (AGPs) [6] The ban of AGP use in many European countries has had a bad effect on the colonization of $C$. perfringens and the prevention of necrotic enteritis in poultry, and the misuse of antibiotics has led to an increase in the prevalence and risk of antibiotic resistance of C. perfringens infection in broiler chickens [7]. Therefore, there has been a growing interest in alternative antimicrobial agents for controlling NE disease. Essential oils (EOs) have been used in treating many diseases because they have potent antimicrobial activities [8-13] and anti-inflammatory effects [14-16]. Recently, several studies have shown the positive impact of EOs on NE caused by C. perfringens in chickens $[17,18]$. Therefore, there has been an increasing interest in finding alternatives for growth promoters and strengthening of the immune system [19]. The aim of this study was to investigate the antibacterial and immunological activities of two EO blends (provided by Animal Wellness Products, Modena, Italy) against a NetB-carrying isolate of C. perfringens both in vitro and in vivo in comparison with commonly used antibiotics.

\section{Results}

\subsection{Disk Diffusion Assay}

The results of the disk diffusion assay are shown in Table 1. Both EOs D and E gave the largest inhibition zone among all treatments. Amoxicillin gave the largest inhibition zone among the antibiotics but not a larger inhibition zone than those of EOs D and $\mathrm{E}$.

Table 1. Growth inhibition zones of different treatments against C. perfringens according to disk diffusion assay.

\begin{tabular}{lll}
\hline Treatment & Inhibition Zone $(\mathbf{m m})$ & Source \\
\hline Essential oil D & 52 & $\begin{array}{l}\text { Animal Wellness } \\
\text { Products/Italy } \\
\text { Animal Wellness } \\
\text { Essential oil E }\end{array}$ \\
Amoxicillin & 40 & Products/Italy \\
Doxycycline & 24 & Bioanalyse/Turkey \\
Tetracycline & 18 & Arab Co. for Medical \\
Enrofloxacin & 17 & Diagnostics/Jordan \\
Penicillin & 16 & Bioanalyse/Turkey \\
Oxytetracycline & 15 & Bioanalyse/Turkey \\
\hline
\end{tabular}

\subsection{Minimal Inhibitory Concentration Assay (MIC) and Minimum Bactericidal Concentration Assay (MBC)}

The obtained results for MICs and MBCs are shown in Table 2. C. perfringens showed higher susceptibility to EOs D and E than other EOs.

Table 2. MICs and MBCs of different treatments against C. perfringens.

\begin{tabular}{lll}
\hline Treatment & MIC & MBC \\
\hline Essential oil A & $1.666 \pm 0.33(\mu \mathrm{L} / \mathrm{mL})$ & NA \\
Essential oil B & $0.833 \pm 0.166(\mu \mathrm{L} / \mathrm{mL})$ & NA \\
Essential oil C & $1.666 \pm 0.33(\mu \mathrm{L} / \mathrm{mL})$ & NA \\
Essential oil D & $0.026 \pm 0.005(\mu \mathrm{L} / \mathrm{mL})$ & $0.026 \pm 0.005(\mu \mathrm{L} / \mathrm{mL})$ \\
Essential oil E & $0.052 \pm 0.010(\mu \mathrm{L} / \mathrm{mL})$ & $0.052 \pm 0.010(\mu \mathrm{L} / \mathrm{mL})$ \\
Essential oil F & $3.333 \pm 0.66(\mu \mathrm{L} / \mathrm{mL})$ & NA \\
Amoxicillin & $0.416 \pm 0.08(\mu \mathrm{g} / \mathrm{mL})$ & $0.416 \pm 0.083(\mu \mathrm{g} / \mathrm{mL})$ \\
\hline
\end{tabular}

NA: not applicable. 


\subsection{Chicks' Performance}

The results of feed conversion ratio are shown in Figure 1. Groups that were treated with either EO D, EO E, or amoxicillin showed a significant decrease in feed conversion ratio $(p<0.05)$ compared with the infected untreated group. There was no significant difference between the EO groups $(p<0.05)$, while a significant difference was observed between the EO E group and the amoxicillin group $(p<0.05)$ and between the EO E group and the control groups (noninfected and untreated groups).

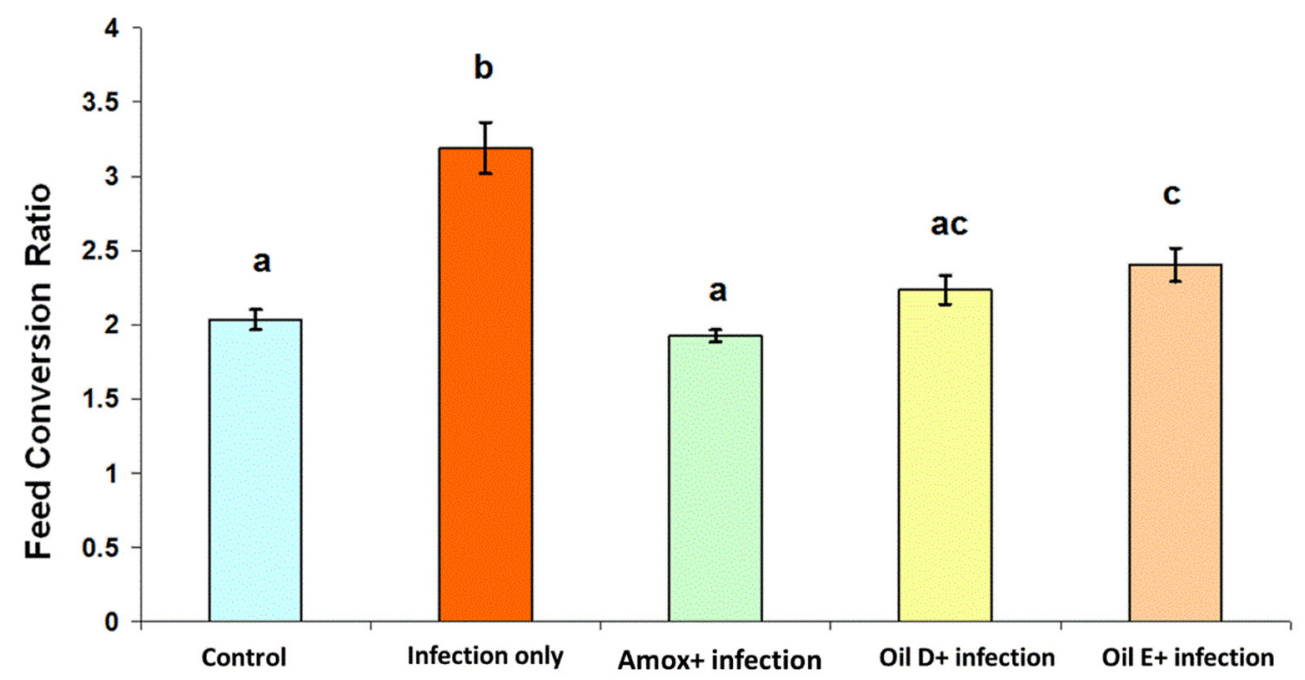

\section{Experimental Groups}

Figure 1. Feed conversion ratio in birds in response to NE caused by C. perfringens infection. The feed conversion ratio was calculated by dividing the average feed intake over the average weight gain per replicate per group. The values are means \pm S.E. Different letters represent statistically significant differences with a $p$-value less than 0.05 .

\subsection{Bacterial Count}

Bacterial count results are presented in Figure 2. The infected untreated group showed an increase in bacterial count compared with all the experimental groups $(p<0.05)$. There was no significant difference between the two groups that received EOs $(p<0.05)$. Amoxicillin decreased the bacterial count significantly when compared with all the other groups $(p<0.05)$. It was also observed that there was no significant difference between the EO E and control groups $(p<0.05)$.

\subsection{Immunological Response}

Immunological response was determined by measuring the IL-1 $\beta$, IFN- $\gamma$, IL-8, IL-10, and IL-17 levels in chicks' serum using ELISA kits. We dealt with the two EOs as one unit because we found that there was no significant difference between them in effecting the immune response $(p<0.05)$. IL-17 level is shown in Figure 3A. The birds treated with EOs showed a significant increase in IL-17 level in comparison with the control and infected untreated groups $(p<0.05)$. IL-10 level is shown in Figure 3B. The birds treated with EOs showed a significant increase in IL-10 level in comparison with the control and infected untreated groups $(p<0.05)$. IFN- $\gamma$ level is shown in Figure 3C. The birds treated with EOs experienced a significant decrease in IFN- $\gamma$ level in comparison with the control and infected untreated groups $(p<0.05)$. IL- $1 \beta$ level is shown in Figure 3D. The birds treated with EOs showed a significant decrease in IL- $1 \beta$ level in comparison with the control and infected untreated groups $(p<0.05)$. IL-8 level is shown in Figure 3E. The birds treated with EOs experienced a significant decrease in IL-8 level in comparison with the infected untreated group $(p<0.05)$. 


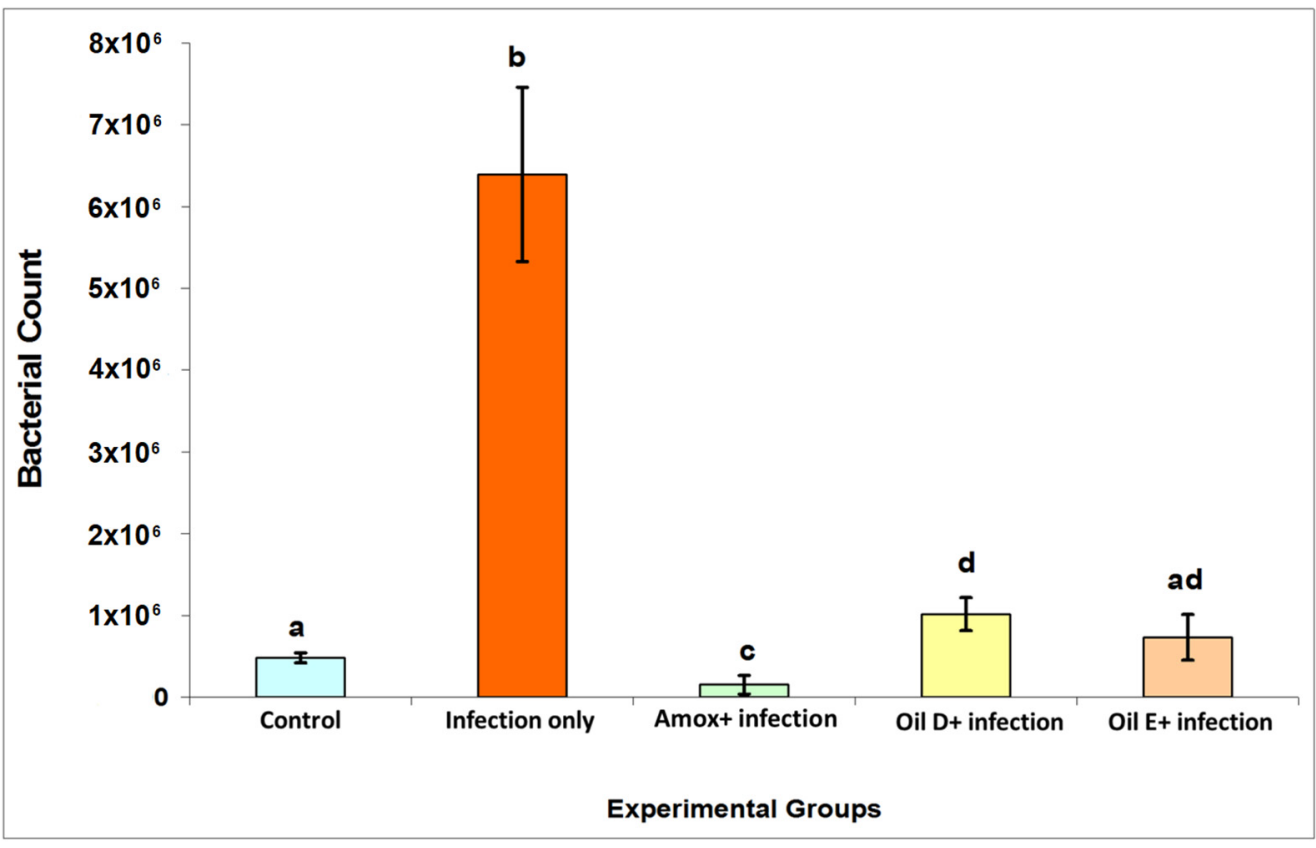

Figure 2. C. perfringens count was recovered from the intestinal contents of the birds with and without NE. All the control groups reflect the basal bacterial counts in the presence of intestinal stressors (nutritional and coccidial overdose vaccination) in the untreated nonexperimentally infected birds. The values are means \pm S.E. Different letters represent statistically significant differences with a $p$-value less than 0.05 .

\subsection{Gross Lesions}

The main lesion features that were adopted by this study are the presence of ulcer in the intestinal mucosa with acute bright-red hemorrhage within the ulcer bed with or without crusting in all parts of the small intestine with brown fluid. The entire length of the small intestine was checked for any lesion, and each part of the small intestine (duodenum, jejunum, and ileum) was evaluated according to Figure 4. Overall, the NE lesion score was measured by calculating the sum for all the separate intestinal portions (duodenum, jejunum, and ileum) (normal $=0$, abnormal $=1$ ); the scores ranged from 0 to 3 . The overall NE lesion score for the entire length of the small intestine is shown in Figure 5 The groups treated with either EO D, EO E, or amoxicillin showed a significant decrease in intestinal lesion score compared with the infected untreated group with no significant difference between these treatments $(p<0.05)$. The control groups had the lowest intestinal lesion score among all the other groups $(p<0.05)$. 
A

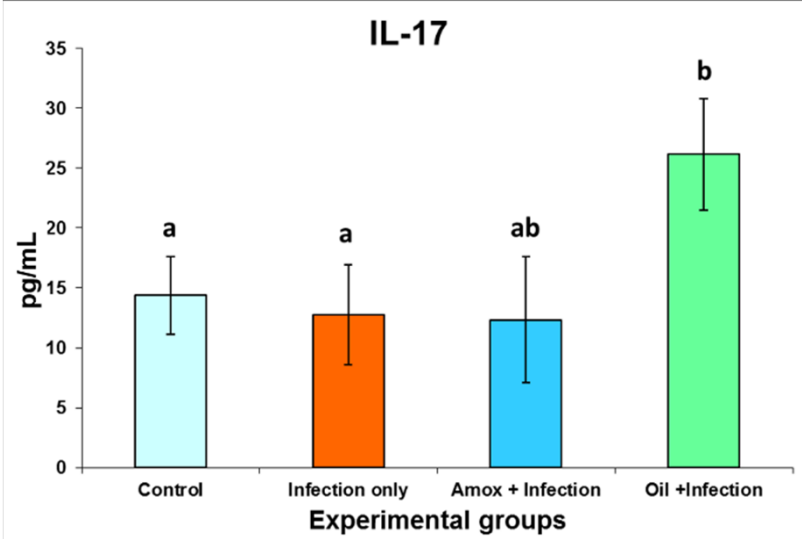

C

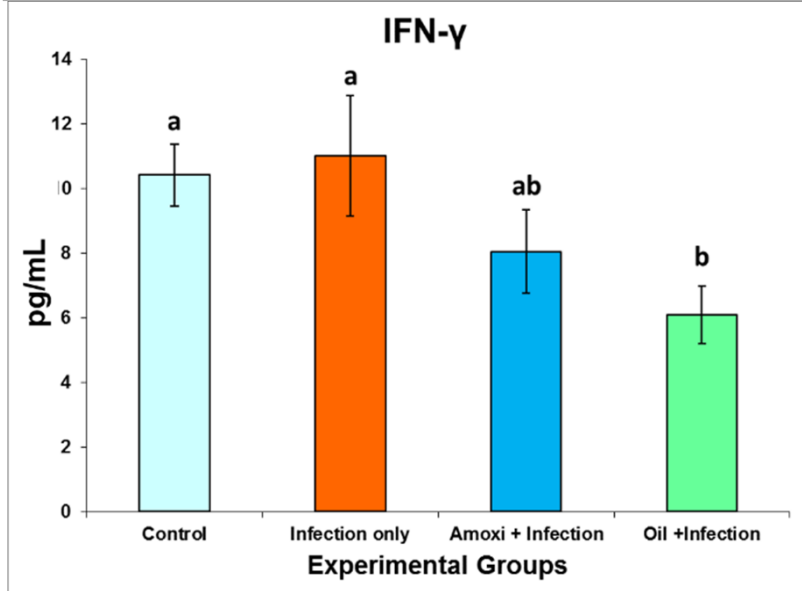

B

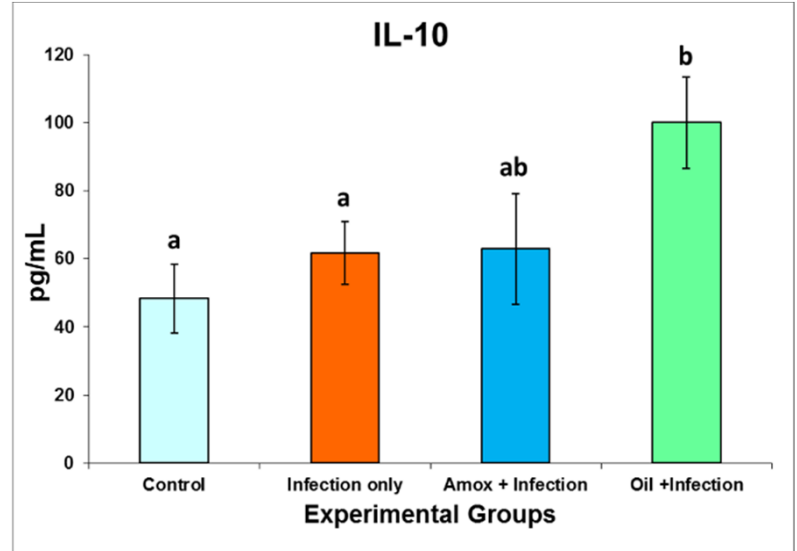

D



E

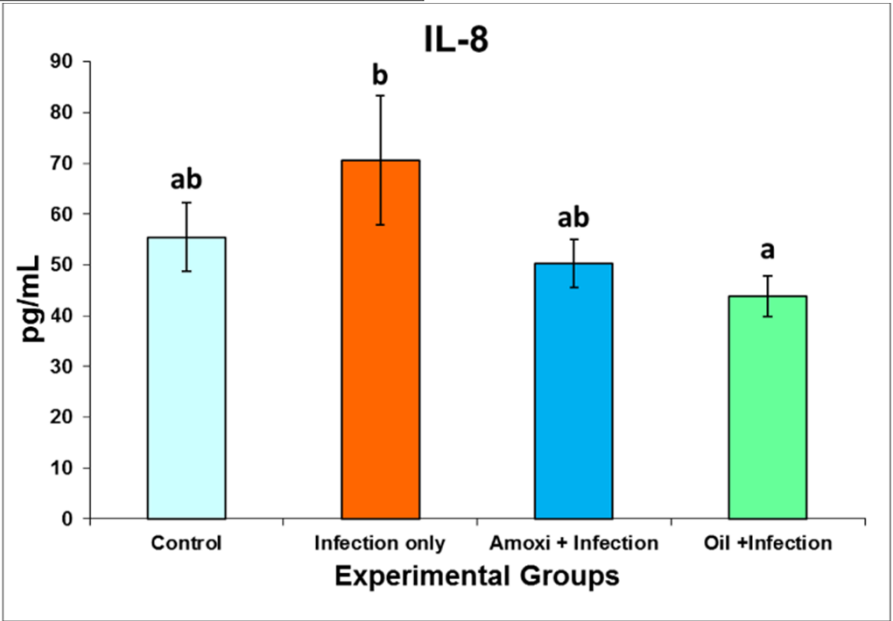

Figure 3. The concentrations of the IL-17 (A), IL-10 (B), IFN- $\gamma$ (C), IL-1 $\beta$ (D), and IL-8 (E) cytokines in comparison with the challenge experimental NE study obtained through ELISA. At 19 days of age, the chickens were infected for 4 continuous days through oral administration of broth cultures of $C$. perfringens. On the second day of $C$. perfringens infection, the chicks were orally administrated the recommended dose of the coccidial vaccine 10 times. The treatment was administrated in drinking water on day 22 and continued for 5 days. Sera were collected at day 27 postchallenge. The values are means \pm S.E. Different letters represent statistically significant differences with a $p$-value less than 0.05 . 


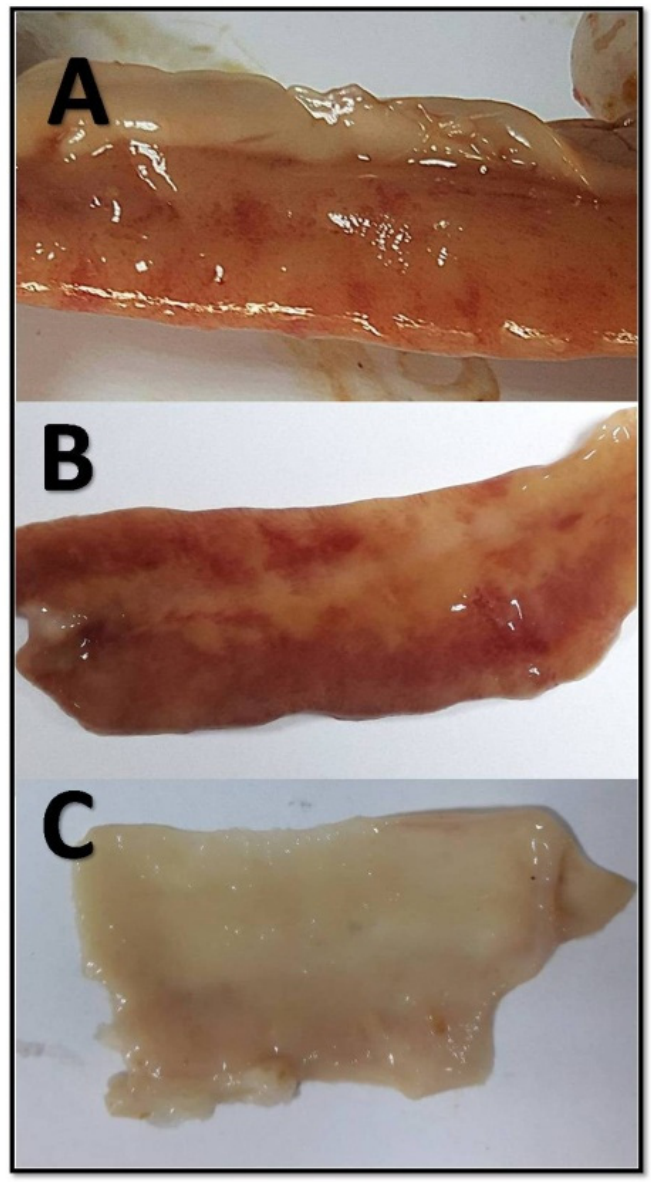

Figure 4. Different lesions of NE in the small intestine. (A) Thickened mucus, variable degrees of serosal blood vessel congestion. (B) Hemorrhage of the intestinal wall, fibrin deposition, and necrotic debris of the mucus membrane. (C) No gross lesions are present.

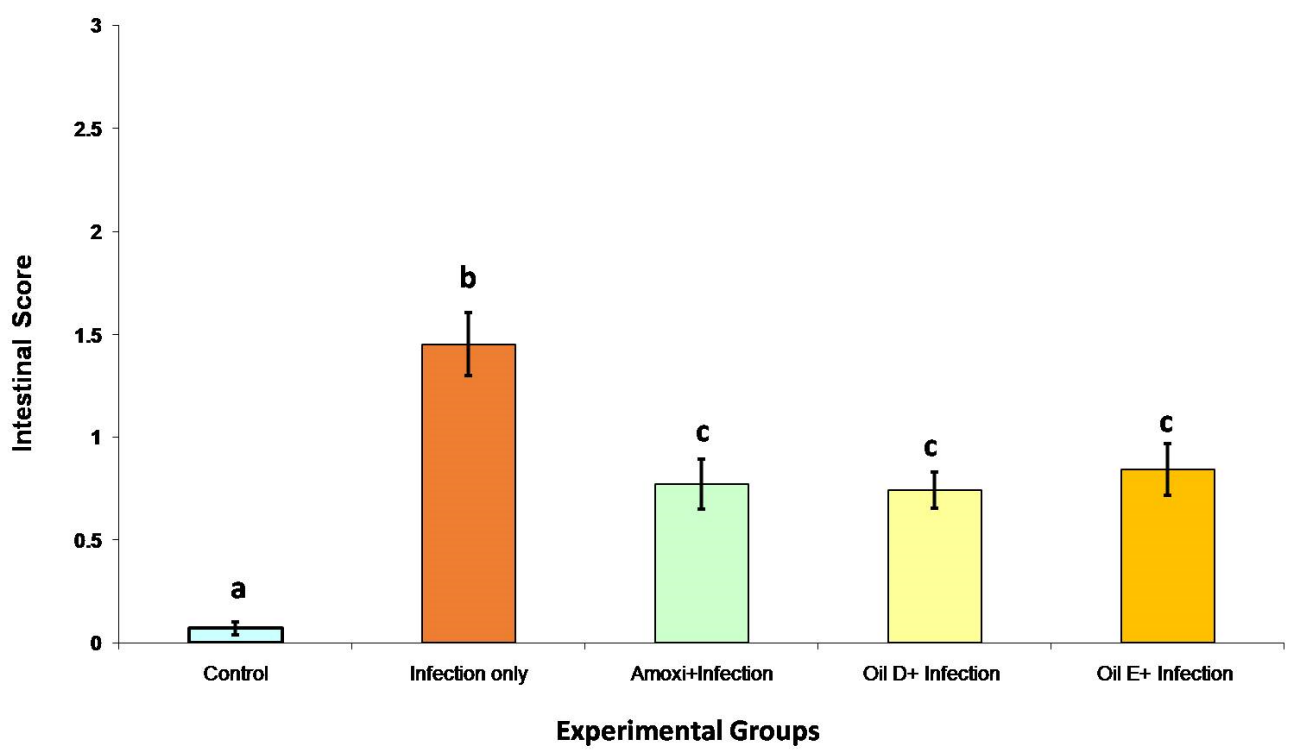

Figure 5. Overall NE lesion score for the entire length of the small intestine. The score sum for all the separate intestinal portions (duodenum, jejunum, and ileum) ranges from 0 to 3 . All the control groups reflect the basal intestinal scores in the presence of intestinal stressors (nutritional and coccidial overdose vaccination). The values are means \pm S.E. Different letters represent statistically significant differences with a $p$-value less than 0.05 . 


\section{Discussion}

The current work was designed to investigate the antibacterial efficacy of two EO blends in the treatment of $C$. perfringens infection in broilers, focusing on their effects on growth performance, bacterial count, gross lesion, and immunological profile. C. perfringens is one of the most deleterious pathogens in the poultry industry worldwide [1]. C. perfringens is an opportunistic bacterium that is present normally in the intestines of healthy broiler chickens with low count (up to $10^{4} \mathrm{CFU} / \mathrm{g}$ ), but under certain conditions, C. perfringens may multiply and overgrow, leading to an increase in bacterial count (up to $10^{7}$ to $10^{8} \mathrm{CFU} / \mathrm{g}$ ), and cause clinical disease [20]. In the current study, we found a significant increase in C. perfringens count in the intestines of the birds in the infected untreated group compared with those in the control groups $(p<0.05)$. As a result of EO treatment, treating the birds with either EO D or E showed a clear decrease in bacterial count in the intestines of the chickens in comparison with those of the infected untreated birds $(p<0.05)$. In the current study, all the control groups showed a level of C. perfringens count in the chickens' intestines, which seems not to cause any pathological changes. Upon model induction and in the presence of intestinal stressors, an increase in bacterial count was clearly observed. This was possibly due to placing the chickens on a high protein diet [20] and the administration of the recommended dose of coccidial vaccine 10 times [21].

Growth-promoting antibiotics have been used for many decades in broilers' feed to enhance chicks' performance. However, the banning of the use of growth-promoting antibiotics in many European Union countries has led to an increase in the prevalence of C. perfringens infection in broiler chicks and an increase in outbreaks of NE [22]. As a result, there is a global trend toward searching for alternative treatments, such as EOs [8-11,16], to limit the emergence and spread of bacterial infections. NE disease provokes lesions and changes in the integrity of the intestine. A study in the US ranged the gross lesions in the small intestine of diseased chickens with NE from superfine and friable to frank and extensive necrotic lesions [23]. In the current study, we scored the gross lesions in the small intestine of diseased chickens with NE from 0 to 3, which are represented in Figure 4. Necrotic lesion severity was negatively correlated with the EO D and E treatments that were introduced to chickens for 5 days after the last dose of $C$. perfringens.

Birds' performance is represented by the feed conversion ratio. As the costs of broiler feed represent about $75 \%$ of the total cost of broiler production [24], the feed conversion efficiency is considered one of the important parameters for broiler production. C. perfringens is a major concern in the poultry industry because it causes economic losses by decreasing birds' performance by increasing the feed conversion ratio and impairing nutrient absorption due to intestinal mucosal damages [25]. The current results support these findings by showing a significant increase in feed conversion ratio in the infected untreated group compared with the control groups $(p<0.05)$. Using EO D, EO E, and amoxicillin as treatments decreased the feed conversion ratio significantly compared with the infected untreated group $(p<0.05)$.

In order to explain the mechanism of EOs' effect on NE, immune response was evaluated in all the experimental groups by measuring several key inflammatory and regulatory cytokines. An enhancement in the gene expression levels of IL-17, which is produced by Th17 cells as a proinflammatory cytokine following NE infection, has been found [26]. On the contrary, Th17 cells that produce IL-17 with IL-10 do not induce tissue inflammation; rather, they may have an anti-inflammatory effect, leading to alleviating the inflammation [27]. This correlation between IL-17 and IL-10 has not been studied in chickens with NE disease. In the present work, we are the first to study the correlation between IL-17 and IL-10 in chickens with NE disease. We found that treating birds with EOs directs the immune system toward an anti-inflammatory pathway by increasing the levels of both IL-17 and IL-10 significantly, compared with the infected untreated and control groups $(p<0.05)$.

The IFN- $\gamma$, IL- $1 \beta$, and IL- 8 cytokines were found to be upregulated in chickens following NE infection $[15,28,29]$ as pro-inflammatory cytokines, which lead to tissue 
inflammation [30-32]. In the current study, treating birds with EOs alleviated the intestinal inflammation through a decrease in the level of the IFN- $\gamma$, IL- $1 \beta$, and IL- 8 cytokines compared with the infected untreated and control groups $(p<0.05)$.

NE causes poor performance due to a decrease in feed digestion and absorption as a result of intestinal mucosal damage. Fibrinonecrotic enteritis is the main histopathological finding in chickens with NE [22,33]. In the current study, diseased chickens had severe fibrinonecrotic necrosis with inflammatory cells in all parts of the small intestine. NE disease affects 2- to 5-week-old broiler chickens and can increase the mortality rate by up to $50 \%$, which results in huge economic losses [34]. In the current study, none of the treated birds died due to NE compared with the $10 \%$ mortality rate in the infected untreated group. In summary, the current study showed that EO blends significantly reduced bacterial count, lowered the FCR, lowered gross lesions, and decreased intestinal inflammation compared with the controls.

\section{Materials and Methods}

\subsection{Essential Oil Composition and the Source of Infection Isolate}

Six commercial EO blends (A-F) were used to determine their minimum inhibitory concentration (MIC) and MBC. All of the EOs were supplied by Animal Wellness Products, Reggio Emilia, Italy. The chemical compositions of the six EOs were previously presented in Gharaibeh et al. [35]. All oils were stored at $4{ }^{\circ} \mathrm{C}$ until used. One C. perfringens isolate was obtained from the Department of Pathology and Public Health, Faculty of Veterinary Medicine, Jordan University of Science and Technology. This isolate was selected among C. perfringens isolates according to the result of a NetB-carrying toxin. The C. perfringens isolate was originally obtained from the intestines of 3- to 5-week-old broiler chicken flocks from Jordan with a history of severe intestinal necrotic lesions [36].

\subsection{Determination of Disk Diffusion Assay}

Disk diffusion assay was performed according to the Clinical and Laboratory Standards Institute (CLSI) [37] with slight modification as previously described by Gharaibeh et al. [35]. Briefly, sterile filter paper discs (Whatman disc, $6 \mathrm{~mm}$ diameter) (Oxoid, Basingstoke, UK) were impregnated with $15 \mu \mathrm{L}$ of the EOs and kept at room temperature for $1 \mathrm{~h}$. Freshly prepared Mueller Hinton broth culture of a C. perfringens NetB-positive toxin isolate (used for challenge) was adjusted to $0.5 \mathrm{McFarland}$ turbidity, which is equivalent to $1 \times 10^{8} \mathrm{CFU} / \mathrm{mL}$, by using a spectrophotometer (Thermo Fisher Scientific, Waltham, MA, USA) at 600 wavelength with 0.132 reading. Then the cultured broth was streaked evenly into a Mueller Hinton agar medium (Oxoid, UK) using a cotton swab in three directions. The EO discs and the antibiotic discs (Table 1) were applied on the Mueller Hinton agar surface and incubated at $37^{\circ} \mathrm{C}$ for $24 \mathrm{~h}$ under anaerobic conditions.

\subsection{Minimal Inhibitory Concentration Assay (MIC) and Minimum Bactericidal Concentration Assay (MBC)}

Disk diffusion assay results clearly showed that amoxicillin carried the best anticlostridial activity among the common commercially antibiotics used. Therefore, amoxicillin was selected to be tested using MIC and MBC assays along with two EOs. MIC and $\mathrm{MBC}$ against a $C$. perfringens NetB-positive toxin isolate (used for challenge) were achieved in triplicate using broth microdilution according to the CLSI method as previously described by Radaelli et al. [38]. Briefly, fresh C. perfringens cultures were grown overnight anaerobically in Reinforced Clostridial broth (Oxoid, UK). Then $50 \mu \mathrm{L}$ of sterile Reinforced Clostridial broth was added to each well of 96-well microplates. After that, $50 \mu \mathrm{L}$ of each of the antimicrobial treatments including the six different EO formulas and amoxicillin were added to each well of the first column of 96-well microplates so that each well of the first column contained a different antimicrobial agent. A twofold serial dilution was used to get the final concentration ranging from 256 to $0.000122 \mu \mathrm{L} / \mathrm{mL}$ for each EO formula, and for amoxicillin, from 256 to $0.125 \mu \mathrm{g} / \mathrm{mL}$. After that, the bacterial broth was adjusted 
to $0.5 \mathrm{McF}$ arland turbidity, which is equivalent to $1 \times 10^{8} \mathrm{CFU} / \mathrm{mL}$, then diluted to 1:100 by adding $0.1 \mathrm{~mL}$ of the bacterial broth to $9.9 \mathrm{~mL}$ of clean broth to get a concentration of $1 \times 10^{6} \mathrm{CFU} / \mathrm{mL}$. Then $50 \mu \mathrm{L}$ of the suspension broth was added to each well of $96-$ well microplates with mixing to get a final concentration of $5 \times 10^{5} \mathrm{CFU} / \mathrm{mL}$ and incubated at $37^{\circ} \mathrm{C}$ for $24 \mathrm{~h}$ under anaerobic conditions. MIC values were defined as the lowest concentration of the compound that inhibited visible bacterial growth after $24 \mathrm{~h}$ of anaerobic incubation. On the other hand, MBC values were determined by culturing $100 \mu \mathrm{L}$ from the first well showing no growth and two wells before on a tryptose sulfite-cycloserine agar medium (Oxoid, UK) with d-cycloserine supplement (Sigma, Ronkonkoma, NY, USA) anaerobically for $24 \mathrm{~h}$.

\subsection{Birds and Housing}

A total of 440 1-day-old Ross broiler chicks were obtained from a commercial hatchery. The chicks were divided into 10 experimental groups (Table 3). Each group was placed in a separate cage, where it was further divided into four replicates with 11 birds per replicate $\left(1 \mathrm{~m}^{2}\right)$. The chicks were raised on antibiotic-free starter feed until 11 days of age. At 11 days old, the feed was changed from starter to grower feed (Table 4). At 19 days old, the chicks were placed on high wheat ration and high fish meal diet (by replacing the soybean meal with fish meal), which was continued for 8 days. This ration is known as a predisposing factor for successful NE model development [20]. The in vivo experiments were carried out according to the recommendations and approval of the Animal Care and Use Committee, Jordan University of Science and Technology (JUST-ACUC).

Table 3. Experimental groups.

\begin{tabular}{llll}
\hline & $\begin{array}{l}\text { C. Perfringens } \\
\text { Challenged }\end{array}$ & $\begin{array}{l}\mathbf{1 0}^{\mathbf{X}} \text { Coccidial } \\
\text { Vaccine Dose } \\
\text { Administration }\end{array}$ & Treatment/Concentration \\
\hline Bird age & 19-22 days & 20 days & 22-26 days \\
Group 1 & None & None & None \\
Group 2 & None & Yes & None \\
Group 3 & None & None & Formula D/high \\
Group 4 & None & None & Formula E/high \\
Group 5 & Yes & Yes & None \\
Group 6 & Yes & Yes & Amoxicillin \\
Group 7 & Yes & Yes & Formula D/high \\
Group 8 & Yes & Yes & Formula D/low \\
Group 9 & Yes & Yes & Formula E/high \\
Group 10 & Yes & & Formula E/low \\
\hline
\end{tabular}

Table 4. Feed formula.

\begin{tabular}{ll}
\hline Feed Type & Kg per Ton \\
\hline Wheat & 512 \\
Corn & 120 \\
Soybean meal & 300 \\
Oil & 25 \\
Ca Carbonate & 9.0 \\
MonoCa Pho & 16.3 \\
Met & 3.5 \\
Thr & 1.0 \\
Lys & 2.5 \\
Salt & 2.0 \\
Na Bicarb & 2.7 \\
Vit/Min & 6.0 \\
Total & 1000 \\
\hline
\end{tabular}




\subsection{Challenge Procedure}

For the challenge experiment, a pilot study was performed to determine the best bacterial isolate and dose to be used. In the challenge experimental NE study, the infection was induced at 19 days of age for 4 continuous days through oral administration of each chick with $0.5 \mathrm{~mL}$ of freshly prepared Mueller Hinton broth cultures of a C. perfringens NetB-positive toxin isolate of $1.2 \times 10^{9}$ per $\mathrm{mL}$, while the control chicks were treated similarly but only received broth free of $C$. perfringens as a placebo. On the second day of $C$. perfringens infection, the chicks were orally administrated the recommended dose of coccidial vaccine (Immucox, Ceva, Libourne, France) (Table 4) 10 times to enhance NE disease development [21].

\subsection{Treatment}

Based on the in vitro results, which clearly showed that EO D and E carried the best anticlostridial activity, EO D and E were selected among the six formulas of EOs, and amoxicillin among the common antibiotics commercially used, to be used as treatments in the in vivo study. The concentrations of the EOs used for the in vivo study were determined according to the $\mathrm{MBC}$ results. The treatment concentrations were 8 times the MBC value. Therefore, from the in vitro experiments, formula $D$ was used at a dilution factor of 1:2000 from stock $(500 \mu \mathrm{L} / \mathrm{L})$, formula $\mathrm{E}$ was tested at a dilution factor of 1:1000 from stock $(1000 \mu \mathrm{L} / \mathrm{L})$, and amoxicillin (Chemifarma S.p.A., Forli, Italy) was used at its highest recommended dose $(0.12 \mathrm{~g} / \mathrm{L})$. The treatment was administrated in drinking water at 22 days of age (on the day clinical signs first appeared) and continued for 5 days.

\subsection{Chickens' Performance}

The birds' performance was evaluated by calculating the feed conversion ratio for all the groups by dividing the average of feed intake (offered feed minus refused feed) per replicate over the average of weight gain for the same replicate and then by calculating the average of all replicates in the same group. The chicks were weighted on the first day of infection and on the day of slaughter (day 27).

\subsection{Immunological Response}

One day after the end of the treatment (day 27), blood samples from 120 birds ( 3 birds from each replicate) were collected from the wing vein into $1.5 \mathrm{~mL}$ Eppendorf tubes, centrifuged at $6000 \mathrm{rpm}$ for $10 \mathrm{~min}$ to obtain the serum, and then stored at $-20^{\circ} \mathrm{C}$. The serum cytokine (IL-1 $\beta$, IFN- $\gamma$, IL-8, IL-10, and IL-17) titers were measured by commercially available ELISA kits (MyBioSource ELISA kits, San Diego, CA, USA) and according to the manufacture's protocol.

\subsection{Bacterial Count}

Three birds from each replicate were slaughtered, and bacterial count was performed by weighting $1 \mathrm{~g}$ of pooled intestinal contents. The contents $(1 \mathrm{~g})$ were then added to $9 \mathrm{~mL}$ of peptone water and mixed well, followed by 10 -fold serial dilutions $\left(10^{-1}-10^{-4}\right)$. An amount of $100 \mu \mathrm{L}$ of each diluted tube was cultured on tryptose sulfite-cycloserine agar media (Oxoid, UK) with d-cycloserine (Sigma, USA) and incubated at $37^{\circ} \mathrm{C}$ anaerobically for $\sim 48 \mathrm{~h}$. At the end of the incubation period, black bacterial colonies were counted [39].

\subsection{Gross Lesion Evaluation}

All the birds were slaughtered, and their small intestines were subjected to gross lesion evaluation, a procedure that was modified from Cooper and Songer [23]. The presence of one or more of the following changes in the small intestines-thickened mucus, variable degrees of serosal blood vessel congestion (Figure 4A), hemorrhage of the intestinal wall, fibrin deposition, and necrotic debris of the mucus membrane (Figure 4B) - was considered an indicator that a bird was positive for necrotic enteritis. On the other hand, the absence of any significant gross lesions within the small intestines was considered an indicator that 
a bird was normal (Figure 4C). Birds that died due to the infection were examined and found to have severe necrotic enteritis lesions in all intestinal tissue parts (Figure 4B).

\subsection{Statistical Analysis}

Statistical analysis was performed using OpenEpi (http:/ /www.openepi.com/Menu/ OEMenu.htm, accessed on 10 March 2018). The results were compared using a two-way analysis of variance (ANOVA), and significant differences among means were tested using Student's $t$-test. Only $p$-values less than 0.05 were considered statistically significant.

\section{Conclusions}

EOs decrease NE disease severity by alleviating the inflammation, decreasing the mortality rate, enhancing birds' performance, decreasing the intestinal C. perfringens count, and alleviating intestinal lesions. Therefore, we conclude that EOs are an effective and safe alternative to antibiotics in chickens when treating NE disease.

Author Contributions: Conceptualization, M.H.G. and M.S.K.; data curation, W.M.H. and M.S.A.; formal analysis, A.N.N., W.M.H. and M.S.A.; funding acquisition, M.H.G. and M.S.K.; investigation, M.S.K. and A.N.N.; methodology, M.H.G. and M.S.K.; project administration, M.H.G. and M.S.K.; resources, M.H.G. and M.S.K.; software, A.N.N.; supervision, M.H.G. and M.S.K.; validation, M.H.G. and M.S.K.; visualization, M.S.K.; writing—original draft, M.H.G., M.S.K. and A.N.N.; writing - review and editing, M.H.G. All authors have read and agreed to the published version of the manuscript.

Funding: This work was funded in part by a grant from the Deanship of Research, Jordan University of Science and Technology (project no. 263/2017), and a grant from Animal Wellness Products, Reggio Emilia, Italy.

Institutional Review Board Statement: The present study was carried out according to the recommendations and approval of the Animal Care and Use Committee, Jordan University of Science and Technology (JUST-ACUC).

Data Availability Statement: All the data generated or analyzed during this study are included in this published article.

Acknowledgments: The authors acknowledge Saad Gharaibeh from the Department of Pathology and Public Health, Faculty of Veterinary Medicine, Jordan University of Science and Technology, for providing us with $C$. perfringens isolates.

Conflicts of Interest: The authors declare no conflict of interest.

Sample Availability: Samples of the compounds are available from the authors.

\section{References}

1. Wade, B.; Keyburn, A. The true cost of necrotic enteritis. World Poult. 2015, 31, 16-17.

2. Moore, R.J. Necrotic enteritis predisposing factors in broiler chickens. Avian Pathol. 2016, 45, 275-281. [CrossRef]

3. Seal, B.S. Characterization of bacteriophages virulent for Clostridium perfringens and identification of phage lytic enzymes as alternatives to antibiotics for potential control of the bacterium. Poult. Sci. 2013, 92, 526-533. [CrossRef] [PubMed]

4. $\quad$ McReynolds, J.L.; Byrd, J.A.; Anderson, R.C.; Moore, R.W.; Edrington, T.S.; Genovese, K.J.; Poole, T.L.; Kubena, L.F.; Nisbet, D.J. Evaluation of immunosuppressants and dietary mechanisms in an experimental disease model for necrotic enteritis. Poult. Sci. 2004, 83, 1948-1952. [CrossRef]

5. Grass, J.E.; Gould, L.H.; Mahon, B.E. Epidemiology of Foodborne Disease Outbreaks Caused by Clostridium perfringens, United States, 1998-2010. Foodborne Pathog. Dis. 2013, 10, 131-136. [CrossRef] [PubMed]

6. Williams, R.B. Intercurrent coccidiosis and necrotic enteritis of chickens: Rational, integrated disease management by maintenance of gut integrity. Avian Pathol. 2005, 34, 159-180. [CrossRef] [PubMed]

7. Van Immerseel, F.; De Buck, J.; Pasmans, F.; Huyghebaert, G.; Haesebrouck, F.; Ducatelle, R. Clostridium perfringens in poultry: An emerging threat for animal and public health. Avian Pathol. 2004, 33, 537-549. [CrossRef] [PubMed]

8. Carezzano, M.E.; Sotelo, J.P.; Primo, E.; Reinoso, E.B.; Paletti Rovey, M.F.; Demo, M.S.; Giordano, W.F.; Oliva, M.M. Inhibitory effect of Thymus vulgaris and Origanum vulgare essential oils on virulence factors of phytopathogenic Pseudomonas syringae strains. Plant Biol. 2017, 19, 599-607. [CrossRef] [PubMed] 
9. Brochot, A.; Guilbot, A.; Haddioui, L.; Roques, C. Antibacterial, antifungal, and antiviral effects of three essential oil blends. Microbiologyopen 2017, 6, e00459. [CrossRef]

10. Mahmoudvand, H.; Saedi Dezaki, E.; Ezatpour, B.; Sharifi, I.; Kheirandish, F.; Rashidipour, M. In Vitro and in Vivo Antileishmanial Activities of Pistacia vera Essential Oil. Planta Med. 2016, 82, 279-284. [CrossRef]

11. Gadisa, E.; Weldearegay, G.; Desta, K.; Tsegaye, G.; Hailu, S.; Jote, K.; Takele, A. Combined antibacterial effect of essential oils from three most commonly used Ethiopian traditional medicinal plants on multidrug resistant bacteria. BMC Complement. Altern. Med. 2019, 19, 24. [CrossRef] [PubMed]

12. Kang, J.; Jin, W.; Wang, J.; Sun, Y.; Wu, X.; Liu, L. Antibacterial and anti-biofilm activities of peppermint essential oil against Staphylococcus aureus. LWT 2019, 101, 639-645. [CrossRef]

13. Bravo Cadena, M.; Preston, G.M.; Van der Hoorn, R.A.L.; Townley, H.E.; Thompson, I.P. Species-specific antimicrobial activity of essential oils and enhancement by encapsulation in mesoporous silica nanoparticles. Ind. Crops Prod. 2018, 122, 582-590. [CrossRef]

14. Du, E.; Wang, W.; Gan, L.; Li, Z.; Guo, S.; Guo, Y. Effects of thymol and carvacrol supplementation on intestinal integrity and immune responses of broiler chickens challenged with Clostridium perfringens. J. Anim. Sci. Biotechnol. 2016, 7, 19. [CrossRef] [PubMed]

15. Wang, S.; Zeng, X.F.; Wang, Q.W.; Zhu, J.L.; Peng, Q.; Hou, C.L.; Thacker, P.; Qiao, S.Y. The antimicrobial peptide sublancin ameliorates necrotic enteritis induced by Clostridium perfringens in broilers. J. Anim. Sci. 2015, 93, 4750-4760. [CrossRef]

16. Gogoi, R.; Loying, R.; Sarma, N.; Munda, S.; Kumar Pandey, S.; Lal, M. A comparative study on antioxidant, anti-inflammatory, genotoxicity, anti-microbial activities and chemical composition of fruit and leaf essential oils of Litsea cubeba Pers from North-east India. Ind. Crops Prod. 2018, 125, 131-139. [CrossRef]

17. Du, E.; Guo, Y. Dietary supplementation of essential oils and lysozyme reduces mortality and improves intestinal integrity of broiler chickens with necrotic enteritis. Anim. Sci. J. 2021, 92, e13499. [CrossRef]

18. Pham, V.H.; Kan, L.; Huang, J.; Geng, Y.; Zhen, W.; Guo, Y.; Abbas, W.; Wang, Z. Dietary encapsulated essential oils and organic acids mixture improves gut health in broiler chickens challenged with necrotic enteritis. J. Anim. Sci. Biotechnol. 2020, 11, 18. [CrossRef] [PubMed]

19. Gharaibeh, M.H.; Shatnawi, S.Q. An overview of colistin resistance, mobilized colistin resistance genes dissemination, global responses, and the alternatives to colistin: A review. Vet. World 2019, 12, 1735-1746. [CrossRef] [PubMed]

20. Drew, M.D.; Syed, N.A.; Goldade, B.G.; Laarveld, B.; Van Kessel, A.G. Effects of dietary protein source and level on intestinal populations of Clostridium perfringens in broiler chickens. Poult. Sci. 2004, 83, 414-420. [CrossRef] [PubMed]

21. Abudabos, A.M.; Yehia, H.M. Effect of dietary mannan oligosaccharide from Saccharomyces cerevisiae on live performance of broilers under Clostridium perfringens challenge. Ital. J. Anim. Sci. 2013, 12, 231-235. [CrossRef]

22. Grave, K.; Kaldhusdal, M.; Kruse, H.; Fevang Harr, L.M.; Flatlandsmo, K. What has happened in Norway after the ban of avoparcin? Consumption of antimicrobials by poultry. Prev. Vet. Med. 2004, 62, 59-72. [CrossRef]

23. Cooper, K.K.; Songer, J.G. Virulence of Clostridium perfringens in an experimental model of poultry necrotic enteritis. Vet. Microbiol. 2010, 142, 323-328. [CrossRef]

24. Saiyed, M.A.; Joshi, R.S.; Savaliya, F.P.; Patel, A.B.; Mishra, R.K.; Bhagora, N.J. Study on inclusion of probiotic, prebiotic and its combination in broiler diet and their effect on carcass characteristics and economics of commercial broilers. Vet. World 2015, 8 , 225-231. [CrossRef] [PubMed]

25. Lovland, A.; Kaldhusdal, M. Severely impaired production performance in broiler flocks with high incidence of Clostridium perfringens-associated hepatitis. Avian Pathol. 2001, 30, 73-81. [CrossRef] [PubMed]

26. Hong, Y.H.; Song, W.; Lee, S.H.; Lillehoj, H.S. Differential gene expression profiles of $\beta$-defensins in the crop, intestine, and spleen using a necrotic enteritis model in 2 commercial broiler chicken lines. Poult. Sci. 2012, 91, 1081-1088. [CrossRef] [PubMed]

27. Lee, Y.; Kuchroo, V. Defining the functional states of Th17 cells. F1000Research 2015, 4, 132. [CrossRef] [PubMed]

28. Athanasiadou, S.; Russell, K.M.; Kaiser, P.; Kanellos, T.; Burgess, S.T.G.; Mitchell, M.; Clutton, E.; Naylor, S.W.; Low, C.J.; Hutchings, M.R.; et al. Genome wide transcriptomic analysis identifies pathways affected by the infusion of Clostridium perfringens culture supernatant in the duodenum of broilers in situ. J. Anim. Sci. 2015, 93, 3152-3163. [CrossRef]

29. Guo, S.; Li, C.; Liu, D.; Guo, Y. Inflammatory responses to a Clostridium perfringens type A strain and $\alpha$-toxin in primary intestinal epithelial cells of chicken embryos. Avian Pathol. 2015, 44, 81-91. [CrossRef] [PubMed]

30. Schoenborn, J.R.; Wilson, C.B. Regulation of Interferon- $\gamma$ During Innate and Adaptive Immune Responses. Adv. Immunol. 2007, 96, 41-101.

31. Lopez-Castejon, G.; Brough, D. Understanding the mechanism of IL-1ß secretion. Cytokine Growth Factor Rev. 2011, 22, 189-195. [CrossRef]

32. Shahzad, A.; Knapp, M.; Lang, I.; Köhler, G. Interleukin 8 (IL-8)-a universal biomarker? Int. Arch. Med. 2010, 3, 11. [CrossRef]

33. Park, J.Y.; Kim, S.; Oh, J.Y.; Kim, H.R.; Jang, I.; Lee, H.S.; Kwon, Y.K. Characterization of Clostridium perfringens isolates obtained from 2010 to 2012 from chickens with necrotic enteritis in Korea. Poult. Sci. 2015, 94, 1158-1164. [CrossRef] [PubMed]

34. Riddell, C.; Konga, X.M. The influence of diet on necrotic enteritis in broiler chickens. Avian Dis. 1992, 36, 499-503. [CrossRef] [PubMed] 
35. Gharaibeh, M.H.; Khalifeh, M.S.; Zattout, E.M.; Abu-qatouseh, L.F. Potential antimicrobial effect of plant essential oils and virulence genes expression in methicillin-resistant Staphylococcus aureus isolates. Vet. World 2020, 13, 669-675. [CrossRef] [PubMed]

36. Gharaibeh, S.; Al Rifai, R.; Al-Majali, A. Molecular typing and antimicrobial susceptibility of Clostridium perfringens from broiler chickens. Anaerobe 2010, 16, 586-589. [CrossRef] [PubMed]

37. CLSI. M100 Performance Standards for Antimicrobial Susceptibility Testing; CLSI: Wayne, PA, USA, 2020; ISBN 610.688.0700.

38. Radaelli, M.; da Silva, B.P.; Weidlich, L.; Hoehne, L.; Flach, A.; da Costa, L.A.M.A.; Ethur, E.M. Antimicrobial activities of six essential oils commonly used as condiments in Brazil against Clostridium perfringens. Braz. J. Microbiol. 2016, 47, 424-430. [CrossRef]

39. Hossain, M.M.; Begum, M.; Kim, I.H. Effect of Bacillus subtilis, Clostridium butyricum and Lactobacillus acidophilus endospores on growth performance, nutrient digestibility, meat quality, relative organ weight, microbial shedding and excreta noxious gas emission in broilers. Vet. Med. 2015, 60, 77-86. [CrossRef] 